\title{
Educação Infantil: O lúdico de acordo com a BNCC
}

\author{
Early Childhood Education: Playfulness according to BNCC \\ Educación Infantil: Diversión según BNCC
}

Recebido: 14/09/2021 | Revisado: 25/09/2021 | Aceito: 26/09/2021 | Publicado: 27/09/2021

\author{
Antônio Veimar da Silva \\ ORCID: https://orcid.org/0000-0003-2080-0307 \\ Universidade Federal da Paraíba, Brasil \\ E-mail: veimar26@hotmail.com \\ Carla Michelle da Silva \\ ORCID: https://orcid.org/0000-0002-1872-5902 \\ Faculdade Única, Brasil \\ E-mail: carla.mic@hotmail.com \\ Jessilene Bezerra Marques \\ ORCID: https://orcid.org/0000-0002-3209-0245 \\ Universidade Estadual do Piauí, Brasil \\ E-mail: jessilene_bz@hotmail.com \\ Wankleber de Farias Silva \\ ORCID: https://orcid.org/0000-0002-7976-2678 \\ Universidade Federal do Piaú, Brasil \\ E-mail: wankleber21@ hotmail.com
}

\begin{abstract}
Resumo
Este artigo tem como tema a Educação Infantil: o lúdico de acordo com a Base Nacional Comum Currícular, na etapa da pré escola. Trata-se de uma pesquisa de campo realizada com 10 professores de uma escola publica da região nordeste do Brasil, realizada através de um questionário, tendo como bases teoricas a Base Nacional Comum Currícular e em autores renomados que discutem o referido tema (pesquisa bibliográfica). O objetivo desta pesquisa é refletir sobre a relevância do lúdico, iluminados pela Base Nacional Comum curricular, na etapa da pré-escola (4 aos 5 anos e 11 meses), na visão de docentes da rede pública de ensino em uma cidade do nordeste do Brasil. Observa-se das respostas das professoras entevistadas que uma parte delas não tiveram interesse em lê a BNCC para conhecimento do referido documento. A maioria das professora acreditam que trabalhar com a ludicidade é a chave para um ensino com aprendizagem significativa enquando uma parte não quer sair da mesmice, querendo continuar na metodologia tradicional o qual já trabalham a tempo. Pode-se notar tambem que a BNCC dar subsidio para que o ensino da Educação Infantil seja atraves da ludicidade, com jogos e brincadeira fazendo com que as crianças aprendam de forma dinâmica, significativa e atrativa.
\end{abstract}

Palavras-chave: Ludicidade; Pré-escola; Base nacional comum curricular.

\begin{abstract}
This article has as theme Early Childhood Education: the playful according to the Common National Curriculum Base, in the pre-school stage. This is a field research carried out with 10 teachers from a public school in the northeast region of Brazil, carried out through a questionnaire, having as theoretical bases the Common National Curriculum Base and renowned authors who discuss the subject (literature research). The objective of this research is to reflect on the relevance of playfulness, illuminated by the Common National Curriculum Base, in the pre-school stage (4 to 5 years and 11 months), in the view of public school teachers in a city in the northeast of Brazil. It is observed from the answers of the interviewed teachers that a part of them had no interest in reading the BNCC to get to know the referred document. Most teachers believe that working with playfulness is the key to teaching with meaningful learning while a part does not want to leave the sameness, wanting to continue in the traditional methodology which they already work on time. It can also be noted that the BNCC subsidizes the teaching of Early Childhood Education through playfulness, with games and games making children learn in a dynamic, meaningful and attractive way.
\end{abstract}

Keywords: Playfulness; Pre school; Common national curriculum base.

\section{Resumen}

Este artículo tiene como tema la Educación Infantil: lo lúdico según la Base Curricular Nacional Común, en la etapa preescolar. Se trata de una investigación de campo realizada con 10 docentes de una escuela pública en la región noreste de Brasil, realizada a través de un cuestionario, teniendo como base teórica la Base Curricular Nacional Común y autores de renombre que discuten el tema (investigación bibliográfica). El objetivo de esta investigación es reflexionar sobre la relevancia de la alegría, iluminada por la Base Curricular Nacional Común, en la etapa preescolar 
(4 a 5 años y 11 meses), en la visión de docentes de escuelas públicas de una ciudad del noreste de Brasil. Se observa a partir de las respuestas de los docentes entrevistados que una parte de ellos no tenía interés en leer el BNCC para conocer el referido documento. La mayoría de los profesores creen que trabajar con alegría es la clave para enseñar con un aprendizaje significativo mientras que una parte no quiere dejar la igualdad, queriendo continuar en la metodología tradicional que ya trabaja a tiempo. También se puede destacar que el BNCC subvenciona la enseñanza de Educación Infantil a través de la lúdica, con juegos y juegos que hacen que los niños aprendan de forma dinámica, significativa y atractiva.

Palabras clave: Alegría; Preescolar; Base de currículo nacional común.

\section{Introdução}

A educação infantil é uma etapa primordial no ensino e aprendizagem visando principalmente a coordenação motora e a socialização das crianças, onde aprendem a igualdade entre pessoas, a espontaneidade, a liderança, entre outros aspectos na formação do cidadão. Essa modalidade de ensino tem ganhado espaço com a Base Nacional Comum Curricular (BNCC) o qual foi homologada em 2017 (Brasil, 2017).

Esse documento ganha destaque, na Educação infantil, com o corpo, gestos e movimentos, apontando as brincadeiras e a ludicidade como protagonista no ensino e aprendizagem das crianças nessa modalidade de ensino. Por este motivo, a presente pesquisa se mostra relevante pois se trata de usar o lúdico como metodologia de ensino levando em consideração a Base Nacional Comum Curricular.

Ao dar início a escrita desse artigo optou-se por dividir a análise discursiva (pesquisa bibliográfica) com os seguintes temas a serem abordados nessa sequência:

1) A BNCC e o Lúdico na Educação Infantil: Algumas contribuições do ensino com o lúdico;

2) A BNCC e seus aspectos norteadores para a Educação Infantil; e

3) Metodologias lúdicas de acordo com a BNCC.

Após a discussão entre os autores, foi descrito a metodologia utilizada na presente pesquisa, os resultados e discussão e as considerações finais sobre o presente trabalho de pesquisa.

Com isso, busca-se o aprofundamento dos temas proposto para ajudar a encontrar as soluções para os seguintes problemas norteadores: os professores da Educação Infantil sabem ensinar atraves do lúdico? Conhecem a BNCC e para que serve? O que esses professores entendem sobre a BNCC? Quais as suas formações? Como trabalhar com a Educação Infantil segundo a BNCC?

Para se chegar às possíveis soluções, aprofundou-se nessa pesquisa na BNCC, como em outros autores que trazem em seus conteúdos de pesquisas importantes argumentos a serem considerados como Almeida (2008); Brennand (2009); Creswell (2010); Gil (2008, 2019) Gouveia, (2013); Lara (2011); e alguns outros que bem contribuíram para enriquecer esta pesquisa.

Assim, esse artigo pretender analisar o cenário atual na vida dos professores da rede pública de ensino sobre o ensino através do lúdico com base na BNCC na Educação Infantil.

\section{Fundamentos Teóricos}

\subsection{A BNCC e o Lúdico na Educação Infantil}

Os estudos teóricos são fundamentais para a construção de uma pesquisa sólida, quanto, mas nos aprofundamos sobre o conteúdo do tema abordado, mais rico o trabalho será. Aqui estaremos trazendo um pouco sobre a ludicidade e a Base Nacional Comum Curricular, enfatizando sobre tudo a parte que traz sobre a educação Infantil, na etapa da pré-escola. 


\subsubsection{Algumas contribuições do ensino com o Lúdico.}

Para entender melhor a presente pesquisa é preciso se aprofundar um pouco sobre a visão de alguns teóricos que discutem sobre o lúdico como uma ferramenta eficaz dentro do processo de ensino, levando em consideração um bom planejamento de acordo com o nível de ensino, que na presente pesquisa, destaca-se a Educação Infantil.

Conhecer sobre a origem do termo ludicidade se faz necessário para que haja uma contextualização. Existem alguns registros, de milhares de anos atrás, precisamente 3.000 anos antes de cristo (A.C), ou seja, muitos anos atrás já existia essa metodologia de ensino, no entanto, não era conhecida com a denominação de ludicidade, porém atualmente, ela é bem conhecida e segundo Almeida,

A educação lúdica contribui e influencia na formação da criança, possibilitando um crescimento sadio, um enriquecimentopermanente, integrando-se ao mais alto espírito democrático enquanto investe em uma produção séria do conhecimento. A sua prática exige a participação franca, criativa, livre, crítica, promovendo a interação social e tendo em vista o forte compromisso de transformação e modificação do meio (Almeida, 2008, p. 41).

Nessa perspectiva o ensino através do lúdico pode proporcionar prazer, diversão e vontade de aprender coisas novas, isso porque o lúdico proporciona esse conforto às crianças, dando confiabilidade, liberdade, a possibilidade de troca de conhecimentos, e aquisição de conhecimentos, diretas e indiretamente.

Kishimoto (2014) discorre em suas pesquisas que o brincar em outros países do mundo é uma forma de emponderamento e resiliência para crianças e adultos, que passam por guerras, desastre naturais e tantas outras formas de sofrimento.

Assim, compreendemos um pouco a importância do lúdico dentro e fora das escolas, visto que vem como uma proposta que agrega valores a aprendizagem dos estudantes, tornando o ensino mais prazeroso e dinâmico aos professores e alunos já que se é um prazer ensinar de forma mais leve e sem tantas cobranças para quea aprendizagem aconteça, pois no tempo certo o estudante aprende em socializaçãocom o outro e consegue ir fazendo prazerosas descobertas.

Nesse sentido, a brincadeira dentro da sala de aula pode proporcionar um maior envolvimento com a participação de todas as crianças nas atividades proporcionando benefícios a todos os envolvidos, possibilitando o conhecimento das necessidades das crianças e consequentemente uma maior mediação pedagógica para quem necessitar mais (Brennand, 2009).

Está metodologia de ensino deve e pode ser usada para todos os alunos, e auxilia o professor que muitas vezes se pergunta como irá mediar o conhecimento para uma criança que tem limitações físicas, ou intelectuais, o autor Brennand (2009) mostra que é possível através do lúdico diminuir as barreiras dessa mediação, podendo ter resultados satisfatórios.

Desta forma, a Educação Infantil pode ser visto como um espaço que propicia este tipo de metodologia, pois dispõe de recursos didáticos, jogos, brincadeiras e espaço físico para que o professor busque realizar atividades bem dinâmicas e envolventes, onde toda a turma sinta prazer em aprender, permitindo uma socialização de todos que estão ali naqueles espaços, trabalhando nessas construções da aprendizagem de forma perceptível ou não.

Para Brennand (2009) a utilização do lúdico na educação infantil possibilita o desenvolvimento integral da criança, pois atraves das brincadeiras as crianças fazem descobertas e constroem a afetividade e interação com os demais alunos.

Assim, é possível utilizar essa ferramenta de ensino como uma metodologia que permita dinamizar as aulas e deixalas mais descontraídas para que todos os educandos participem e aprendam de forma significativa com a interação com seus colegas. Nesse sentido, o ensino lúdico dar ao professor e ao ensino formal no geral uma possibilidade de mediar aprendizagem de uma forma mais concreta e menos cansativa como a que nos propõe o ensino tradicional que é o inverso do que traz a proposta do ensino lúdico. 


\subsubsection{A BNCC e seus aspectos norteadores para a Educação Infantil}

A Base Nacional Comum Curricular veio para agregar qualidade a mediação do ensino, este documento importante em seu conteúdo, traz habilidades e objetivos que possibilitam ao profissional docente ter um ponto de partida bem fundamentado para realizar o planejamento e uma boa execução de suas aulas.

Se tiramos um pouco do tempo para ler o conteúdo ali registrado, veremos que tudo o que está sistematizado na BNCC, não é à toa; está fundamentado em documentos como a Lei de Diretrizes e Bases da Educação de 1996 (Brasil, 1996), Pelo Plano Nacional de Educação de 2014 e na constituição federal de 88, que expressa em seu artigo 205, “A educação, direito de todos e dever do Estado e da família, será promovida e incentivada com a colaboração da sociedade, visandoao pleno desenvolvimento da pessoa, seu preparo para o exercício da cidadania e sua qualificação para o trabalho" (Brasil, 1988).

É preciso ter consciência dos direitos e deveres, saber da importância da aprendizagem e do dever de ensinar. Família, estudantes, profissionais da educação, enfim todos os envolvidos devem entrar em consenso sobre a importância de seu papel na vida dos educandos, só assim a aprendizagem possa acontecer de forma gradual e significativa. Na BNCC também existe o pacto federativo que garante, igualdade, diversidade e equidade, três relevantes instrumentos de democracia.

Também é fato e importante destacar as competências gerais da BNCC, que estão sistematizadas em 10 pontos que devem ser lidos e jamais esquecidos, por ser conscientes da importância dos mesmos para o desenvolvimento dos objetivos da BNCC, como está expresso no documento já na área voltada a educação Infantil que descreve:

Ao longo da Educação Básica - na Educação Infantil, no Ensino Fundamental e no Ensino Médio -, os alunos devem desenvolver as dez competências gerais da Educação Básica, que pretendem assegurar, como resultado do seu processo de aprendizagem e desenvolvimento, uma formação humana integral que vise à construção de uma sociedade justa, democrática e inclusiva. (Brasil, 2017, p. 25)

Nessa modalidade como se pode notar, é na Educação Infantil que a BNCC mostra a importância do desenvolvimento das dez competências. Nesse sentido, a BNCC vem justamente aprimorar os Parâmetros Curriculares Nacionais (PCNs) visando um ensino por competências, e pode ser com o fato de os objetivos e habilidades estarem divididos em três momentos, primeiro para bebês ( 0 a 1 anos e 6 meses de nascido), segundo para crianças bem pequenas (de 1 ano e 7 meses a 3 anos e 11 meses de nascido) e por último, de crianças pequenas (que estão na faixa etária entre 4 anos e 5 anos e 11 meses) (Brasil, 2017), sendo esse último o foco da presente pesquisa.

Nesta primeira fase de aprendizagem devem ser assegurados 6 direitos dentro da aprendizagem dos estudantes que são: Conviver, Brincar, Participar, Explorar, Expressar e Conhecer-se. E com base nesses direitos de aprendizagem iremos encontrar alguns campos norteadores contidos na BNCC que são: $O$ eu, o outro e o nós; corpo, gestos e movimentos; traços, sons, cores e formas; escuta, fala, pensamento e imaginação e espaços, tempos, quantidades, relações e transformações (Brasil, 2017, p. 27).

Dentro desses campos são definidos objetivos da aprendizagem e desenvolvimento que são aplicados com base nas três etapas já citadas acima, considerando a idade certa do desenvolvimento infantil que é tão estudado até hoje, em vista de uma aprendizagem de acordo com o desenvolvimento dos estudantes. Pois como trás Piccinin (2012),

[...] a base para as aprendizagens humanas está na primeira infância. Entre o primeiro e o terceiro ano de idade a qualidade de vida de uma criança tem muita influência em seu desenvolvimento futuro e ainda pode ser determinante em relação às contribuições que, quando adulta, oferecerá à sociedade. Caso esta fase ainda inclua suporte para os demais desenvolvimentos, como habilidades motoras, adaptativas, crescimento cognitivo, aspectos 
sócio emocionais e desenvolvimento da linguagem, as relações sociais e a vida escolar da criança serão bemsucedidas e fortalecidas. (Piccinin, 2012, p. 38)

Assim, conclui-se que as fases do desenvolvimento são importantíssimas e quando pensado neste documento para nortear as ações no ensino básico, foi relevante considerar as fases do desenvolvimento em vista de uma qualidade no ensino dos envolvidos, além de ser a BNCC um documento relevante para que os professores tenham um suporte ao planejar com maior possibilidade de sucesso na aprendizagem dos estudantes, principalmente na Educação Infantil.

Devemos salientar também o fato da educação infantil durante um longo tempo ser apenas um período preparatório para que a criança fosse inserida na educação básica que tinha seu início no ensino fundamental, vejamos o que traz a BNCC a este respeito.

Com a Constituição Federal de 1988, o atendimento em creche e pré-escola às crianças de zero a 6 anos de idade torna-se dever do Estado. Posteriormente, com a promulgação da LDB, em 1996, a Educação Infantil passa a ser parte integrante da Educação Básica, situando-se no mesmo patamar que o Ensino Fundamental e o Ensino Médio. E a partir da modificação introduzida na LDB em 2006, que antecipou o acesso ao Ensino Fundamental para os 6 anos de idade, a Educação Infantil passa a atender a faixa etária de zero a 5 anos (Brasil, 2017, p.35).

Sendo assim, a pré-escola é uma fase não apenas fundamental dentro do processo de ensino mais, uma etapa do ensino hoje garantida e obrigatória por lei, por isso contida dentro do documento Base Nacional Comum Curricular, como uma etapa do ensino básico.

\subsubsection{Metodologias lúdicas de acordo com a BNCC}

Para que se possa realizar uma aula ou mesmo colocar um plano em pratica deve-se pensar em como fazer isso, por isso a necessidade de planejamento. Nesse sentido, é necessário pensar o, passo a passo, que se deve realizar, visando o aprendizado significativo dos educandos de forma sistemática pautadas em as ações e uma metodologia para se colocar o planejamento em prática. Assim a autora Valdemarin (2010) descreve:

O método de ensino é apresentado como o recurso pedagógico capaz de atender às demandas da sociedade, formando indivíduos portadores das habilidades básicas, como ler, escrever, calcular, e que valoriza o progresso científico e industrial de modo a dar-lhe prosseguimento por meio da formação escolar. (Valdemarin, 2010, p. 21).

A metodologia que usamos pode ser positiva ou negativa, dependendo de nossa intencionalidade, na educação, mais necessariamente na educação Infantil a metodologia mais utilizada na atualidade é a metodologia lúdica, e quando nos deparamos com algumas habilidades da educação Infantil percebemos isso, veja o que diz uma delas: (EI03CG02) Demonstrar controle e adequação do uso de seu corpo em brincadeiras e jogos, escuta e reconto de histórias, atividades artísticas, entre outras possibilidades (Brasil, 2017, p. 49).

As brincadeiras livres ou dirigidas são muito importantes na Educação Infantil, assim como os brinquedos, geralmente $\mathrm{cm}$ uma finalidade educativa trabalha o desenvolvimento físico, cognitivo e o motor das crianças. Além de ser uma forma prazerosa, que não traz em sua essência a obrigatoriedade de decifrar letras, códigos e números, que são essenciais para leitura, escrita e conhecimento de mundo, mas que, porém, estão bem presentes em cada brincadeira e brinquedo, bem como nos estímulos verbais dado pelo professor. Nesse sentido, Oliveira (2000) afirma:

O brincar, por ser uma atividade livre que não inibe a fantasia, favorece o fortalecimento da autonomia da criança e contribui para a não formação e até quebra de estruturas defensivas. Ao brincar de que é a mãe da boneca, por exemplo, a menina não apenas imita e se identifica com a figura materna, mas realmente vive intensamente a situação de poder gerar filhos, e de ser uma mãe boa, forte e confiável (Oliveira, 2000, p. 19). 
Ainda podemos destacar os jogos que assim como as brincadeiras propiciam uma interação e uma maior curiosidade nos estudantes, estimulando os porquês e ali aprendendo de forma leve e descontraída, no objetivo de aprendizagem (EI03ET07). Relacionar números às suas respectivas quantidades e identificar o antes, o depois e o entre em uma sequência (Brasil, 2017, p. 54). Essas aprendizagens mais voltadas a área das exatas, nos possibilita trabalhar vários jogos como de memória, podendo esta relacionando os números as quantidades e tantos possibilidades de jogos comprados ou de sucata que o professor pode estar produzindo e realizando essa mediação de forma lúdica. Pensando assim, Lara (2009) destaca que:

Os jogos, ultimamente, vêm ganhando espaço dentro de nossasescolas numa tentativa de trazer o lúdico para dentro da sala de aula.A pretensão da maioria dos professores com a sua utilização é a de tornar as aulas mais agradáveis com o intuito de fazer com que a aprendizagem torne-se algo fascinante. Além disso, as atividades lúdicas podem ser consideradas como uma estratégia que estimula oraciocínio levando o aluno a enfrentar situações conflitantes relacionadas com o seu cotidiano (Lara, 2009, p. 17).

Nesta parte da fundamentação teórica, foram citados apenas dois objetivos do conhecimento voltados a Educação Infantil (pré-escola) contidos na BNCC, mas já pode-se perceber que este documento traz propostas bem lúdicas, indicando ao professor objetivos a serem desenvolvidos no decorrer das aulas em vista da aprendizagem do aluno, com qualidade e ao mesmo tempo, sem tornar o ensino uma obrigatoriedade cansativa aos olhos de uma criança, pois como traz os autores a seguir:

A ludicidade, tão importante para a saúde mental do ser humano é um espaço que merece a atenção dos pais e educadores, pois é o espaço para expressão mais genuína do ser, é o espaço e o direitode toda a criança para o exercício da relação afetiva com o mundo, com as pessoas e com os objetos (Ferreira; Silva; Reschke, 2021, p.6).

Resta nos apenas salientar como está se dando na pratica o estudo pelo docentes e uso da Base Nacional Comum Curricular e as metodologias lúdicas em suas práticas, para compreender cada vez melhor a relação da BNCC e das metodologias lúdicas.

\section{Metodologia}

Este estudo baseou-se em uma pesquisa teórica e de Campo, é uma pesquisa exploratória e descritiva possuindo uma abordagem qualitativa. Estudo de Campo, procura o aprofundamento de uma realidade específica. É basicamente realizada por meio da observação direta das atividades do grupo estudado e de entrevistas com informantes para captar as explicações e interpretações do ocorrem naquela realidade (Gil, 2008).

A pesquisa qualitativa é emergente, portanto não pré-configurada. Diversos aspectos surgem durante o estudo e as questões podem mudar à medida que o pesquisador descobre o que perguntar. É essencialmente interpretativa, ou seja, não é possível evitar as interpretações pessoais nas análises dos dados (Creswell, 2010).

A pesquisa exploratória tem como objetivo principal o aprimoramento de ideias ou a descoberta e intuições, proporcionando maior familiaridade com o problema, em vistas de torná-lo mais explícito ou a construir hipótese. A pesquisa descritiva objetiva descrever características de determinada população ou fenômeno ou, então, estabelecer relações entre variáveis (Gil, 2019).

A pesquisa ocorreu com 10 professores (a) de instituições de ensino de escolas públicas na etapa de Educação infantil (pré-escolar) em um município do Nordeste do Brasil. Professores estes de diferentes faixas etárias e tempo de experiência na 
área.

O processo de coleta de dados aconteceu individualmente, por meio de aplicação de um questionário, com uso de perguntas com alternativas, as informações adquiridas com a aplicação, foram sistematizadas em figuras.

O processo de análise dos dados consistiu em extrair sentido dos dados dos textos ou falas. Inicialmente os dados foram preparados para análise, sendo aprofundados em seu entendimento, interpretados em seus significados mais amplos seguindo os passos propostos por Creswell (2010).

Antes da aplicação dos questionários, certificou-se que tanto as análises como a divulgação dos mesmos estariam respaldado legalmente através de consentimento escrito pelos profissionais envolvidos.

O tema foi escolhido, considerando a importância da Base Nacional Comum curricular dentro dos processos de ensino como documento norteado na educação, fazendo uma relação com a metodologia lúdica que vem cada dia mais mostrando- se ser um caminho de mediação que gera resultados muito positivos na aprendizagem dos educandos.

\section{Resultados e Discussão}

Para o alcance do que almejamos nesta pesquisa, se fez uma amostragem com 10 professores (as) atuantes na educação Infantil, (pré-escola), do ensino público do município de Novo Oriente Ceará. Para preservar a identidade dos mesmos, se fez uso de nomes fictícios no presente artigo e os resultados obtidos encontram-se em tabelas e nos resultados como segue.

Ao aplicar o questionário relativo a proposta de pesquisa do referido trabalho obteve-se o seguinte resultado por parte das 10 docentes (nomeadas aqui de A, B, C, D, E, F, G, H, I e J), que em sua totalidade são mulheres.

Quando questionadas se as referidas professoras conheciam a Base Nacional Comum Curricular (Figura 1), todas as entrevistadas, $100 \%$, responderam que sim, que conhecia o referido documento.

Figura 1. Conhecem, ou já ouviram falar sobre a Base Nacional Comum Curricular?

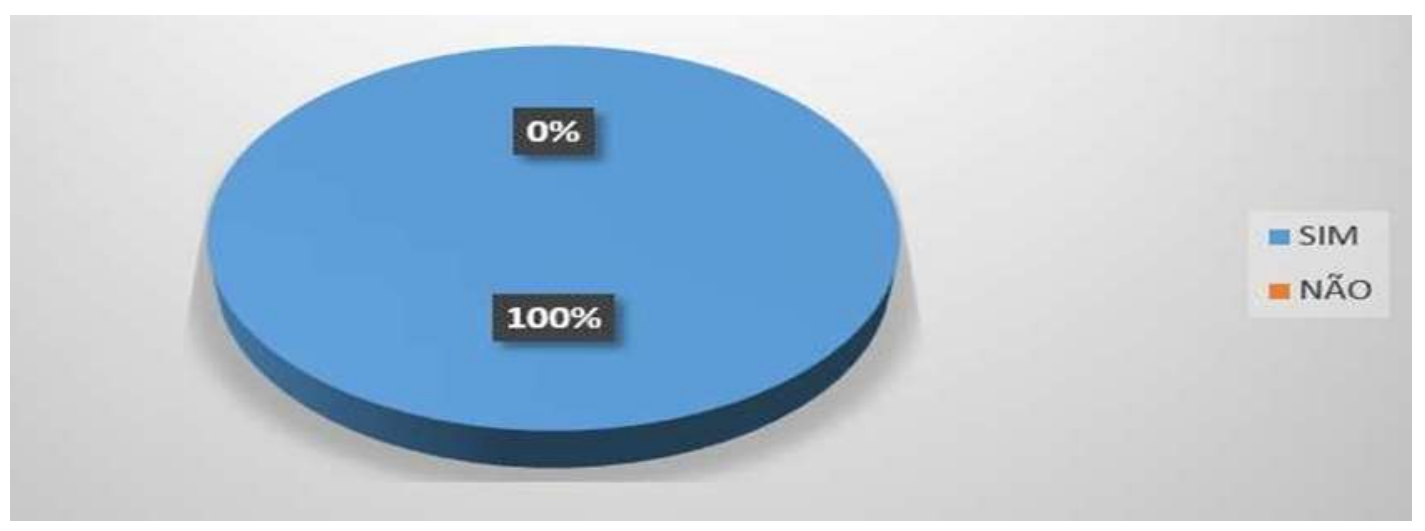

Fonte: Dados da Pesquisa de campo (2021).

Quando questionadas de conhecia a BNCC na integra (Figura 2), observa-se que 40\% das entrevistas foram sinceras em responder que não conheciam o conteúdo do referido documento na íntegra. O conhecimento sobre a BNCC é de suma importância pois através de sua leitura nota-se que na BNCC o lúdico (brincadeira heulística) se aproxima mais de sua metodologia do que distanciamento sobre o mesmo (Duque, 2020) 
Figura 2. Conhecimento sobre a BNCC na integra.

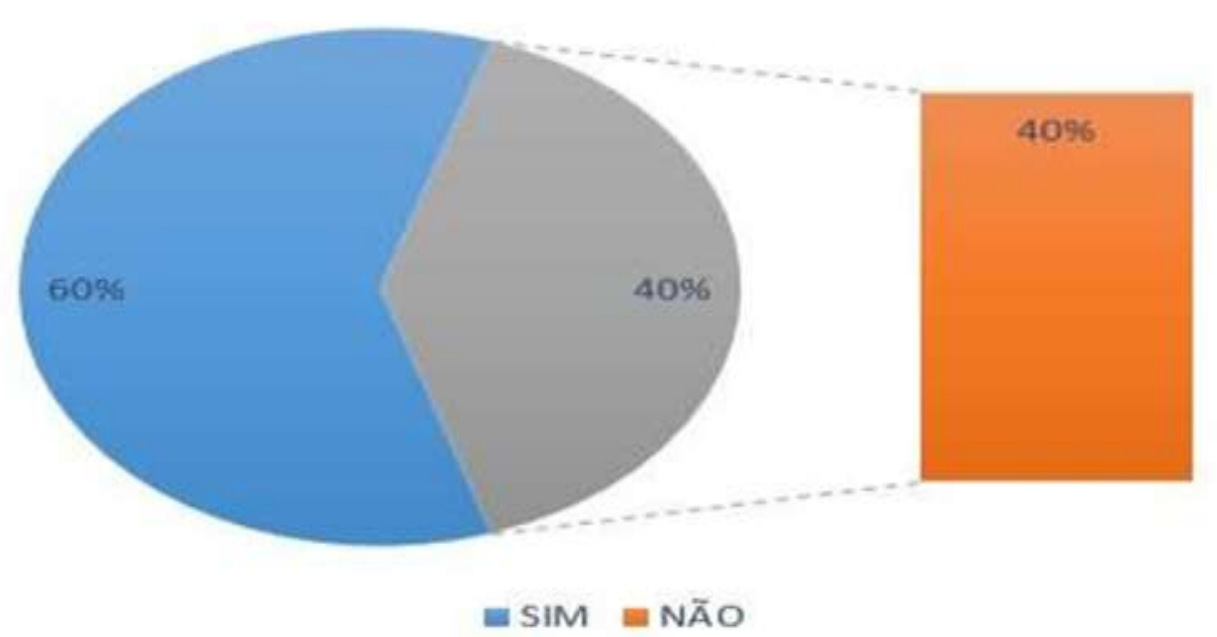

Fonte: Pesquisa de campo (2021).

Observa-se ainda que $60 \%$ das docentes conhecem o documento na integra, mostrando a preocupação em sua atuação e em seu conhecimento sobre o tema, o que se pode induzir que essa arte dos professores se preocupam com a preparação de suas aulas afim de que seus alunos possam ter o melhor nas aulas da Educação Infantil dentro da perspectiva na BNCC. Uma das professoras “ $D$ ” justifica sua reposta de não ter lido o documento na integra da seguinte maneira:

"Até gostaria e sei que é muito importante para um pedagogo saber cada passo no que diz respeito a BNCC, mas infelizmente ainda não tenho o total conhecimento sobre a Base Nacional Comum Curricular, mas nunca é tarde para se aprofundar os conhecimentos em relação a mesma”. (Professora "D”, 2021)

Visto que a referida professora mostrou-se preocupada por não conhecer o documento na integra e afirmando que nunca e tarde para que se possa melhorar na leitura e com isso em suas respectivas aulas na Educação infantil, foi questionado se para elas se o conhecimento do referido documento seria importante para a pratica docente na Educação Infantil (Figura 3).

Figura 3. O conhecimento da BNCC é importante para a prática docente na Educação Infantil.

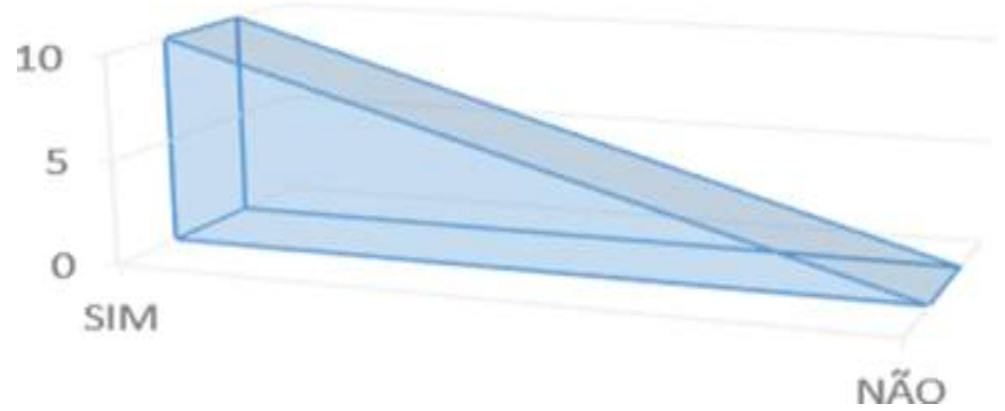

Fonte: Pesquisa de campo (2021).

Observa-se que mesmo as professoras que afirmaram nao conhecer a BNCC na integra, respondem que sim, ou seja, $100 \%$ das entrevistadas ressalta a importância do conhecimento do presente documento para a sua prática de sala de aula na Educação Infantil.

Dentre essas professoras, destaca-se a professora “C! "Afirmando que: “A BNCC é o documento muito importante, e 
que foi criado justamente, pensando no planejamento efetivo, pautada nas competências e habilidade que os alunos devem ter em todas as etapas de seus aprendizados (Professora "C', 2021). Outra professora complementa dizendo que a BNCC é um documento que orienta e auxilia, rege e garante uma Educação de qualidade para todo o país". (Professora "H”, 2021).

Nota-se das falas das professoras que o referido documento é muito importante para todos os professores, pois o mesmo serve de base no planejamento das aulas. Nesse sentido, Souza (2020), ressalta que nos planejamentos das aulas devem ser levados em consideração as competências e habilidades por faixa etária e por etapa de ensino conforme redigido e explicado na Base Nacional Comum Curricular, mostrando mais uma vez a importância do conhecimento desse documento.

Quando questionadas se no planejamento das aulas, elas costumam consultar a BNCC, já que o referido documento norteia o campo de atuação levando em consideração os objetivos e as habilidades ao qual os discentes devem adquirir em cada etapa de ensino (Figura 4), apenas $80 \%$ fazem tal consulta.

Figura 4. Utilização de consulta a BNCC no planejamento das aulas da Educação Infantil.

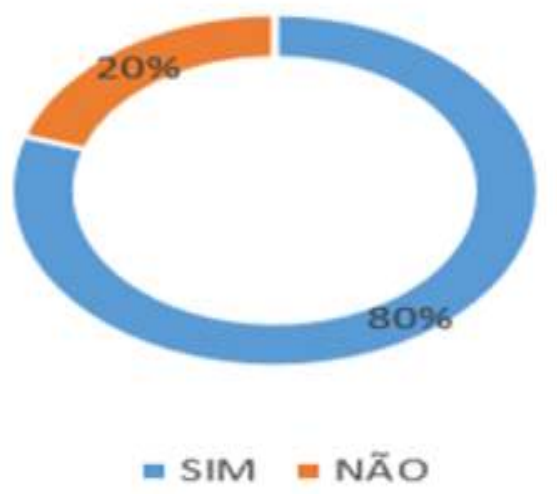

Fonte: Pesquisa de campo (2021).

É importante notar a disparidade das respostas dadas pelas professoras, pois sabem da importância do presente documento, mas nem todas conhecem o documento na integra, depois todas, $100 \%$, afirmam que acreditam na importância do documento na vida dos profissionais da educação, em especial os professores que atuam na Educação Infantil, mas, no entanto, $20 \%$ preparam suas aulas sem a preocupação de verificar o que a BNCC propõe para a modalidade o qual essas professoras fazem parte.

Quando indagadas sobre a BNCC e sua atuação voltada para a Educação Infantil, no que diz respeito ao ensino pelos professores e a aprendizagem dos alunos dessa etapa (Figura 5), 100\% afirmaram que sim, mas vimos anteriormente que nem todas têm o conhecimento e outras que ao preparar suas aulas não usam o documento para nortear suas práticas. 
Figura 5. Os campos de atuação voltados para a educação infantil na etapa da pré-escola, conseguem nortear o trabalho docente em vista da aprendizagem do aluno na etapa da pré-escola?

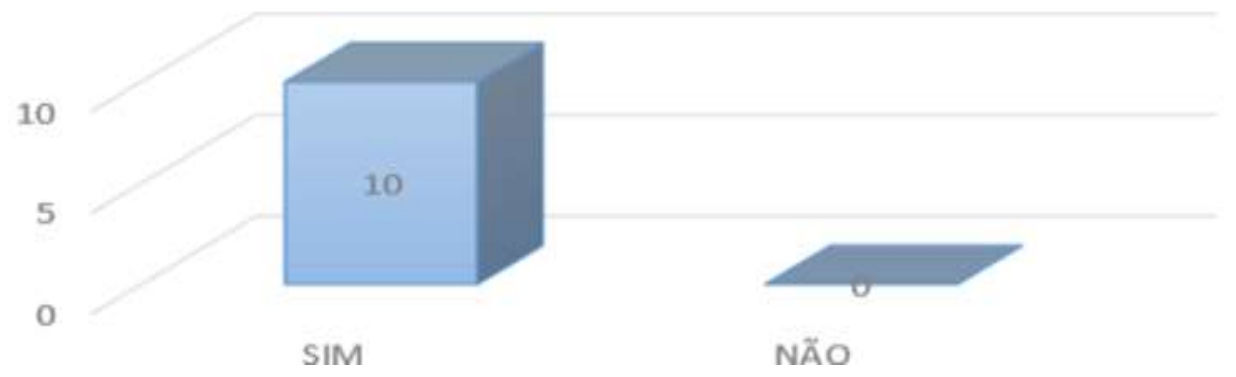

Fonte: Pesquisa de campo (2021).

Por outro lado, pode-se observar na fala de uma das professoras que os planos de aulas do município já têm o esqueleto com as planilhas com o foco na BNCC, com suas estruturas, campos, objetivos e habilidade a serem trabalhada dentro do planejamento (Professora “A”, 2021). Nesse sentido, o município já possui um modelo a ser seguindo que segundo a professora já é pautado na BNCC, e por esse motivo, as outras professoras não tiveram o interesse em lê o documento em si (uma possível explicação).

Mesmo com esse ponto levantado por uma das professoras, não se justifica o desconhecimento de alguns desses professores sobre o conteúdo da BNCC, visto que o mesmo foi criado para ajudar e nortear o ensino e aprendizagem de todas as etapas de ensino, inclusive a Educação infantil, o qual é o foco dessa pesquisa. O professor tem que estar ciente que ele é o mediador do conhecimento dos seus educandos e que ele precisa encontrar maneiras para que a aprendizagem significativa ocorra (Biasi, 2019), diminuindo as diferenças, trabalhando a igualdade, criatividade, dinamismo, entre outros aspectos o qual os alunos devem aprender para usar nas series e etapas posteriores.

Entendido que a BNCC é de suma importância na preparação das aulas de todos os professores, principalmente da Educação Infantil, nortear-se-á, as próximas perguntas sobre a relação do lúdico e sua atuação/relação com a BNCC.

Quando questionadas se elas consideravam as metodologias lúdicas eficazes para a mediação da aprendizagem na Educação Infantil (Figura 6), $60 \%$ das professoras responderam que sim, que o ensino através das metodologias lúdicas se mostra eficazes para essa etapa de ensino. Do ponto de vista de Oliveira (2012, p. 202), utilizar o lúdico como o "brincar é algo que se aprende em sociedade, o contato com a cultura, por meio do professor e dos recursos que ela apresenta, faz avançar significativamente a qualidade da brincadeira (da ludicidade)".

Figura 6. Considera as metodologias lúdicas eficazes para mediação da aprendizagem na Educação Infantil?

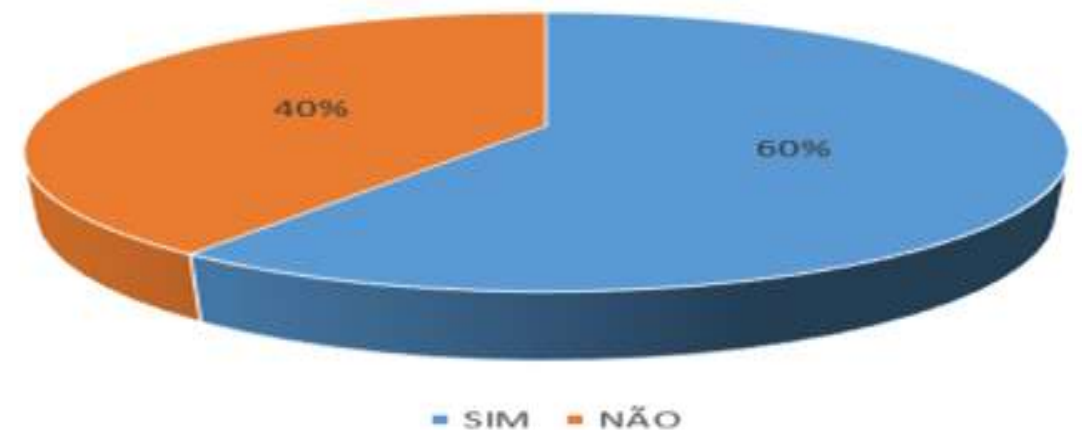

Fonte: Pesquisa de campo (2021). 
Dos $40 \%$ que responderam não, na presente pergunta, pode-se observar o que a professor "B" e "F" responderam:

Não é que desconsidero a eficácia da metodologia lúdica, porém é relevante trazer que existem muitos aspectos da metodologia tradicional que geram resultados positivos na aprendizagem dos estudantes, então acredito num misto destas metodologias de ensino. (Professora "B", 2021)

Sei que é importante o uso do lúdico na sala de aula na Educação Infantil, mas para se planejar uma aula diferença nessa etapa de ensino leva muito tempo e tem que ser levado em consideração o pós e os contras. Não ganhamos suficiente para prepararmos uma aula diferente que chame a atenção dos alunos. Somo pagas para ensinar, mas no contrato não diz que tem que ser através do lúdico (Professor "F", 2021)

Outra professora ainda completa:

Trabalho com o lúdico, mas de forma esporádica, tipo uma vez por semana e as vezes a cada 15 dias. Uso as duas metodologias, a tradicional e a construtivista, mas procuro sempre saber se meus alunos estão aprendendo os conteúdos que devem aprender, tiro todas as dúvidas independente das metodologias que uso no dia-a-dia. Acho que isso que importa, se faço o meu trabalho (Professora "I", 2021).

Das falas das professoras pode-se notar que a preocupação das mesmas é trabalhar na educação infantil de qualquer maneira, mesmo usando o método tradicional de ensino. Elas acreditam que ensinando os alunos a socialização, o companheirismo, a autonomia e autoconfiança mesmo que de modo tradicional é o que importa. Nota-se ainda que elas acreditam na metodologia lúdica, mas não querem ter o trabalho de preparar uma aula diferente e nem tão pouco gasta para fazer uma aula diferente.

Essas professoras devem repensar a sua prática pedagógica, o seu jeito de ensinar, de planejar e reescrever-se como um professor reflexivo e voltar-se para o fazer diferente, pois a ludicidade através de jogos e brincadeira na educação infantil não é meramente um brincar. Vygotsky afirma que a brincadeira como ludicidade é:

(...) a brincadeira cria uma zona de desenvolvimento iminente na criança. Na brincadeira, a criança está sempre acima da média da sua idade, acima de seu comportamento cotidiano; na brincadeira, é como se a criança estivesse numa altura equivalente a uma cabeça acima da sua própria altura. A brincadeira em forma condensada contém em si, como na mágica de uma lente de aumento, todas as tendências do desenvolvimento; ela parece tentar dar um salto acima do seu comportamento comum Vygotsky (2008, p.35).

Mas de uma coisa elas tem razão. Conforme afirma Souza (2020), a brincadeira como uma ferramenta lúdica em sala de aula não deve ser realizada apenas para o divertimento das crianças, mas sim, para a educação delas, na construção de seus conhecimentos, na opção de escolha, na liberdade de expressão, ganhando liberdade na tomada de decisão, de negociação de interação entre outras crianças e em seu crescimento pessoal e intelectual.

Como afirma Winnicott (1975. p. 63) "é no brincar, e somente no brincar, que o indivíduo, criança ou adulto, pode ser criativo e utilizar sua personalidade integral: e é somente sendo criativo que o indivíduo descobre o seu eu (self)", Assim é necessário ciar espaços para que as crianças brinquem e descubra suas potencialidades, usando a sua imaginação e sua criatividade.

Nesse contexto, foi questionado as mesmas se ao mediar os conteúdos dentro da sala de aula, na Educação Infantil, se acreditavam mais na metodologia lúdica ou nas tradicionais de ensino (Figura 7). 
Figura 7. Qual a metodologia mais eficaz ao mediar os conteúdos na Educação Infantil, as lúdicas ou as tradicionais?

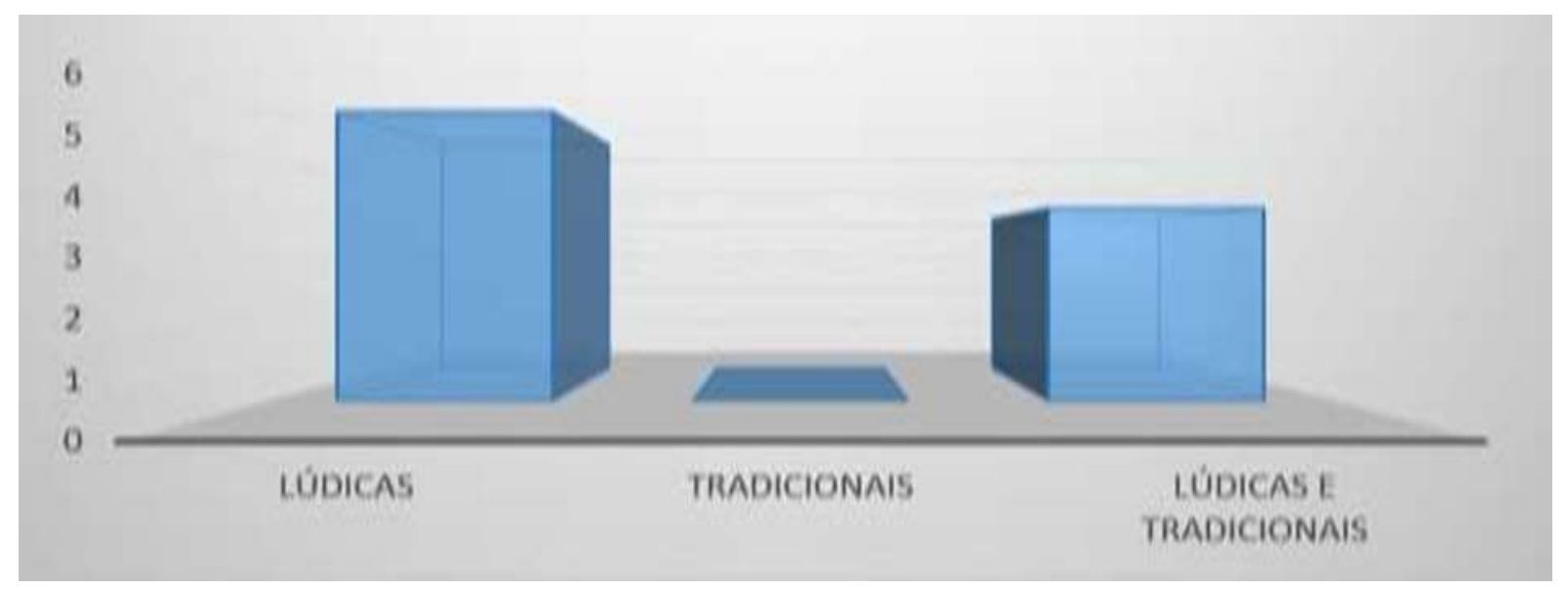

Fonte: Pesquisa de campo (2021).

Observa-se da figura acima, que $60 \%$ das entrevistadas afirmam que o lúdico é uma metodologia eficaz, como podemos ver nessa justificativa da Professora "A": "Nas metodologias lúdicas é notório o interesse do aluno, motivação e participação, o conteúdo não deve ser extinto ambos se complementam". Mais se faz relevante perceber que destas $40 \%$ tem o pensamento mostrado anteriormente pela professora "B", "F" e "I" ao acreditar que devem ser usadas as duas metodologias pois as duas tem eficácia dependendo do conteúdo a ser trabalhado. Outra professora destaca ainda que, "As metodologias lúdicas comprovam o desenvolvimento no aprendizado da criança, com o complemento e a junção com o tradicional permite que tenhamos bons resultados ao mediar os conteúdos, porém cada sala de aula tem sua vivência e realidade" (Professora "D", 2021).

Buscando identificar o que as professoras sabem da BNCC, indagou ainda se na BNCC é proposta mais metodologias lúdicas ou tradicionais (Figura 8), e pode-se verificar que $80 \%$ das professoras acreditam que a BNCC propõe mais metodologias lúdicas do que tradicionais.

Figura 8. Com base na BNCC, é proposto metodologias mais lúdicas ou mais tradicionais?

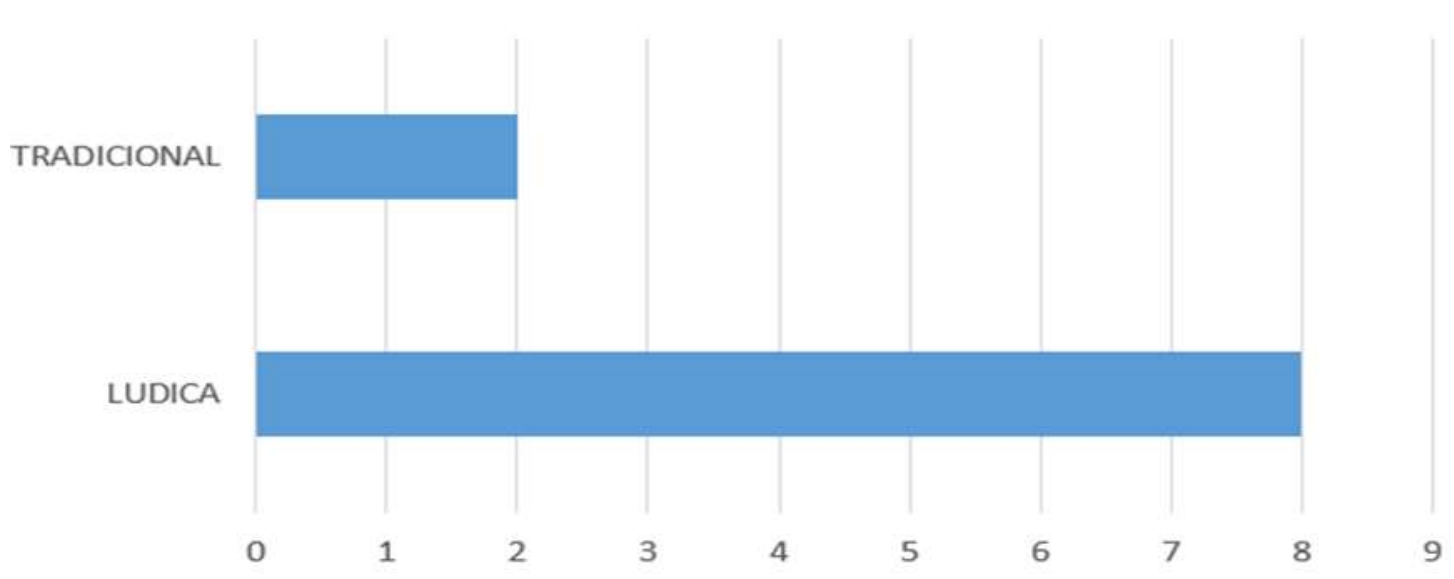

Fonte: Pesquisa de campo (2021).

Mesmo verificado nas respostas anteriores onde $40 \%$ das professoras afirmaram não conhecer a BNCC na íntegra, nota-se que algumas delas acreditam que a BNCC opta por mais metodologias lúdicas do que metodologias tradicionais. Notase que algumas dessas professoras se contradiz ao longo dos questionamentos. A entrevistada " $D$ " fala o seguinte ao justificar 
a sua resposta: "A ludicidade, pois é a partir da brincadeira que se desenvolve as crianças". Outra professora afirma ainda: “sem dúvida nenhuma que são as metodologias lúdicas, pois as crianças aprendem brincando, se socializando e o professor deve sar essa oportunidade aos alunos, de se inseri na sociedade e aprender o máximo possível, sendo o aprendizado oportunizado pelo professor em sala de aula (Professora “J”, 2021).

$\mathrm{Na}$ última pergunta, também relacionada com a metodologia lúdica e a BNCC, foi perguntado de elas acreditavam que os campos de atuação, os objetivos e as habilidade expostos na BNCC, possibilitam o uso de Metodologia lúdicas na hora de planejar as aulas (Figura 9), obtendo $100 \%$ afirmativo (sim).

Figura 9. Vocês acreditavam que os campos de atuação, os objetivos e as habilidade expostos na BNCC, possibilitam o uso de Metodologia lúdicas na hora de planejar as aulas.

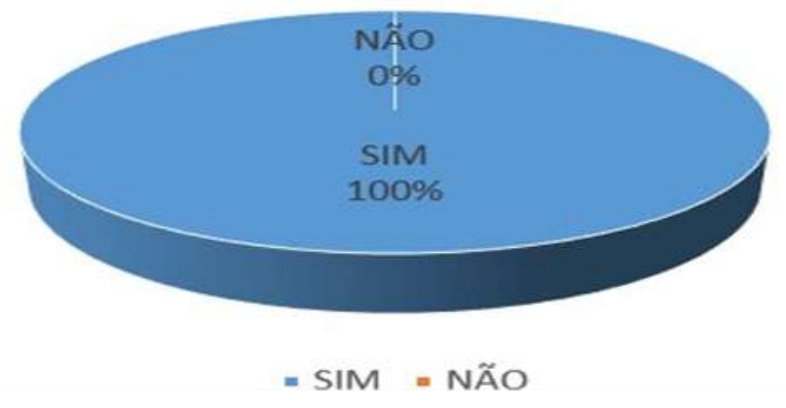

Fonte: Pesquisa de campo (2021).

Confirma-se mais uma vez a relevância do tema da pesquisa aqui realizada como podemos verificar no gráfico acima. Como diz Sommerhalder e Alves, (2011. p.15), através dos jogos e brincadeiras:

[..] a criança busca alternativas para as dificuldades e/ou problemas que vão surgindo[...] É assim que ela testa seus limites e seus medos, é assim que ela satisfaz seus desejos. É assim também que ela aprende e constrói conhecimentos, explorando, experimentando, inventando, criando. Em outros termos, é assim que ela aprende o significado e o sentido, por exemplo, da cooperação, da competição, [...] é assim que ela consegue reconhecer valores e atitudes como respeito ao outro etc.

E notória a necessidade do conhecimento sobre a BNCC, principalmente para a Educação Infantil, e como foi visto na presente pesquisa esses professores devem estudarem a BNCC e a utilizar na hora de preparar suas aulas. Os professores devem ser uma pessoa reflexiva e buscar sempre melhorar como pessoa e como profissional que é.

\section{Considerações Finais}

Ao finalizar está pesquisa muito ficou desta experiência, enquanto pesquisadora incansável dentro do campo da educação, o tema proposto veio de encontro com o objetivo da pesquisa.

Conseguimos responder os questionamentos que nos inquietavam sem deixar outros fluírem ao conseguir sanar os que foram expostos na pesquisa. Assim pudemos observar que muitos profissionais nem mesmo tem conhecimento a relevância da base Nacional Comum Curricular enquanto instrumento norteador do trabalho docente, provavelmente se levarmos questionamentos bem simples, muitos não conseguiram responder devido a salta de contato com este tão importante instrumento da educação.

Embora a metodologia lúdica seja muito falada pelos profissionais da educação, muitos ainda desconhecem a sua real intencionalidade, visto que quando usamos jogos e brincadeiras com nossos alunos estamos bem mais que querendo preencher 
Research, Society and Development, v. 10, n. 12, e479101220599, 2021

(CC BY 4.0) | ISSN 2525-3409 | DOI: http://dx.doi.org/10.33448/rsd-v10i12.20599

o tempo de aula, mais promovendo momentos de aprendizagens.

Se os profissionais da educação conseguirem fazer a relação em seus planejamentos entre os campos de atuação da BNCC e o uso das metodologias lúdicas a tendência será ganhos na aprendizagem discente de forma prazerosa e com uma intencionalidade que fará diferença na educação.

Concluímos, portanto, que é preciso formação, em torno da necessidade de que os profissionais docentes ao planejar suas aulas tenham conhecimento dos conteúdos sistematizados na BNCC, em vista de proporcionar aos estudantes uma educação de qualidade, sendo hoje a metodologia lúdica uma das formas do fazer pedagógico que tem gerado muitos frutos positivos

\section{Referências}

Almeida, P. N. de. (2008). Educação lúdica: técnicas e jogos pedagógicos. Loyola. 296 p.

Biasi, A. L. (2019). A ludicidade na educação infantil jogos, brinquedos e brincadeiras. Revista Educar FCE. Ed. 20, 1(1), 89-91.

Brasil. Constituição (1988). Constituição da República Federativa do Brasil. Senado, 1988. http://www.planalto.gov.br/ccivil_03/consti tuicao/constituicaocompilado.htm.

Brasil. (1996). Lei de Diretrizes e Bases da Educação Nacional. Lei nº 9.394/ 1996, de 20 de dezembro de 1996. Estabelece as diretrizes e bases da educação nacional. Diário Oficial da União. Brasília, DF, 23 dez. http://www.planalto.gov.br/ccivil_03/leis/19394.htm.

Brasil. (2017). Base Nacional Comum Curricular: Educação Infantil e Ensino Fundamental. Brasília: MEC/Secretaria de Educação Básica. http://basenacionalcomum.mec.gov.br/images/BNCC_EI_EF_110518_versaofinal_site.pdf.

Brennand, E. G. de G.; \& Rossi, S. J. (2009) Trilhas do aprendente. Ludicidade e desenvolvimento da criança II. Ed. Universidade/UFPB, João Pessoa, v.4.

Creswell, J. W. (2010). Projeto de pesquisa: métodos qualitativo, quantitativo e misto. Artmed, 296 p.

Duque, L. A. (2020). A base nacional comum curricular da educação infantil (BNCC) e a concepção do brincar heurístico: aproximações ou distanciamentos. TCC (Licenciatura em Pedagogia). Universidade de Caxias do Sul. 41p.

Ferreira, J. de F., Silva, J. A., \& Reschke, M. J. D. (2021). A importância do lúdico no processo de aprendizagem. https://www2.faccat.br/ portal/sites/default/files/A\%20IMPORTANCIA\%20DO\%20LUD ICO\%20NO\%20PROCESSO.pdf

Gil, A. C. (2019). Métodos e Técnicas de Pesquisa Social. (7a ed.), Atlas, 248p.

Gil, (2008). Métodos e técnicas de pesquisa social. (6a ed.), Atlas, 220p.

Gouveia, F. C. (2016). Altmetria: métricas de produção científica para além das citações. Liinc em Revista, 9, $214-227$. http://dx.doi.org/10.18617/liinc.v9i1.569.

Kishimoto, T. M. (2014). Jogos, brinquedose brincadeiras do Brasil. Espacios en Blanco. Revista de Educación, (24), 81-105.

Lara, C. M. (2011). Jogando com a Matemática na Educação Infantil e nas Séries Iniciais. Editora Rêspel, 200 p.

Lara, Â. M. de B. (2009). Infância e educação na obra de Johann Heinrich Pestalozzi: “Cartas sobre educação infantil”. In: sarat, M. (org.) Fundamentos Filosóficos da Educação Infantil. (2a ed.), 93-106.

Oliveira, V. B. de (org). (2000). O brincar e a criança do nascimento aos seis anos. Vozes, 324p.

Oliveira, Y. D. (2012). A docência na educação infantil e o espaço para brincar. Práxis educacional UESB, 8(12). http://periodicos.uesb.br/index. php/praxis/article/viewFile/744/716.

Piccinin, P. V. (2012). A intencionalidade do trabalho docente com as crianças de zero a três anos na perspectiva Histórico-Cultural. 2012.76 fls. Trabalho de Conclusão de Curso (Graduação em Pedagogia) - Universidade Estadual de Londrina, Londrina.

Sommerhalder, A. \& Alves, F. D. (2011). Jogo e a educação da infância: muito prazer em aprender. CRV, 15-29.

Souza, M. B. D. de. (2020). Contribuições da BNCC para a Educação Infantil: perspectivas de ensino-aprendizagem na pré-escola. Revista Científica Multidisciplinar Núcleo do Conhecimento. Ano 05, Ed. 10, 6, 108-120. https://www.nucleodoconhecimento.com.br/pedagogia/contribuicoes-da-bncc.

Valdemarin, V. T. (2010). História dos métodos e materiais de ensino: a escola nova e seus modos de uso. Cortez, 224p.

Vigotski, L. S. (2008). A brincadeira e seu papel no desenvolvimento psíquico da criança. Revista Virtual de Gestão de Iniciativas Sociais. 23-36. https://atividart.files.wordpress.com/2016/05/a-brincadeira-e-seu-papel-no-desenvolvimento-psiquico-da-crianc3a7a.pdf

Winnicott, D. W. (1975). O brincar e a realidade (J. O. A. Abreu, Trad.). Imago, 310p. 